\title{
FORMAÇÃO DE PROFESSORES DE CIÊNCIAS QUANTO ÀS TEMÁTICAS ASTRONOMIA E INFORMÁTICA: REFLEXÕES E POSSIBILIDADES
}

\author{
Fernando Temporini Frederico ${ }^{1}$, Dulcinéia Ester Pagani Gianoto ${ }^{2}$ \\ ${ }^{1}$ Mestrado em Educação para a Ciência e a Matemática - UEM. ${ }^{2}$ Docente do Programa de Pós-graduação em \\ Educação para Ciência e a Matemática - Mestrado e Doutorado - UEM. E-mail: fer.fred@bol.com.br
}

\section{RESUMO}

Este estudo é parte dos resultados de uma pesquisa qualitativa para obtenção do título de Mestre no Programa de Pós-Graduação em Educação para a Ciência e a Matemática, da Universidade Estadual de Maringá - PR. O objetivo central do trabalho foi utilizar dois softwares livres para ensinar conceitos de astronomia a um grupo de alunos do 9o ano do Ensino Fundamental, em uma escola pública paranaense. Neste sentido, percebeu-se a necessidade de verificar se os professores que lecionam a disciplina de Ciências na escola onde ocorreu a pesquisa possuem formação mínima tanto em astronomia, como em informática. Os resultados mostraram que a maioria dos professores entrevistados não possuem formação inicial nem continuada sobre as referidas temáticas.

Palavras-chave: ensino de Ciências, formação de professores, astronomia, informática.

\section{INTRODUÇÃO}

Durante a pesquisa de mestrado, que buscou, dentre outros fatores, verificar a viabilidade de se utilizar dois softwares livres para ensinar conceitos de astronomia para um grupo de alunos do nono ano do Ensino Fundamental, algumas questões se destacavam, a saber: os professores de Ciências que lecionam astronomia no Ensino Fundamental possuem formação em astronomia? E quanto às tecnologias? Será que os educadores possuem a mínima formação necessária para realizar atividades e desenvolver ações utilizando recursos informatizados? Para tentar responder a essas questões, algumas ações foram desenvolvidas com o intuito de verificar se os educadores que lecionam a disciplina de Ciências e, consequentemente, o conteúdo de astronomia, possuem formação nessa área, bem como, verificar se os mesmos dominam o mínimo necessário do sistema operacional Linux $^{1}$ (presente nos laboratório de informática das escolas da rede estadual paranaense).

Altet (2000, p. 25), ao definir o "professor profissional", caracteriza-o como um indivíduo autônomo, dotado de competências específicas e de determinadas especializações baseadas em conhecimentos racionais, "reconhecidos pela ciência, legitimados pela Universidade, ou de conhecimentos explicitados, oriundos da prática". Nesse sentido, como o professor poderá 
desenvolver ações pedagógicas acerca de determinados conteúdos (conhecimentos) se o mesmo não possuir formação para tal? Para tentar esclarecer algumas dessas questões, este trabalho abordou:

a) Entrevista com professores de Ciências que lecionam astronomia;

b) Discussões a respeito da Hora Atividade;

\subsection{Metodologia}

Ao propor desenvolver este estudo, o local escolhido como ambiente de pesquisa, foi a própria escola, envolvendo 6 professores de Ciências de uma escola pública da rede estadual paranaense.

Astronomia é um dos conteúdos que compõem o currículo da disciplina de Ciências, que por sua vez é lecionada nos anos finais do Ensino Fundamental. Entretanto, geralmente quem leciona esta disciplina, nesta modalidade de ensino são professores que possuem formação em Ciências Biológicas - Biologia.

Neste sentido, os 6 professores que participaram desta pesquisa, foram entrevistados, buscando analisar se os mesmos possuíam formação inicial, ou, continuada sobre a temática astronomia, uma vez que lecionam conteúdos ligados à este tema no Ensino Fundamental.

Além disso, buscou verificar também, se estes docentes apresentavam domínio acerca dos computadores presentes nos laboratórios de informática na escola na qual atuam, uma vez que os mesmos são operados pelo sistema operacional Linux.

Além da entrevista com os referidos professores, buscou-se também, analisar o diálogo de 11 professores que participaram da HAI - Hora Atividade Interativa, proposta pela SEED Secretaria Estadual de Educação do Estado do Paraná, com o intuito de promover o diálogo de professores de Ciências de todo o estado, justamente sobre o "Ensino de Astronomia no Ensino Fundamental".

Esta pesquisa se enquadra como qualitativa, onde Mazzoti e Gewandsznajder (1998) afirmam que uma de suas características mais marcantes é utilizar o ambiente natural como fonte de dados. A mesma foi submetida ao Comitê permanente de Ética em Pesquisa com Seres Humanos (COPEP), aprovada sob no 03014912.3.0000.010. 


\subsection{Entrevista com professores de Ciências: Análise e Discussões}

A entrevista se baseou em 6 (seis) questões relacionadas à formação dos entrevistados (denominados, aqui, como: Prof1, Prof2, Prof3, Prof4, Prof5 e Prof6), especialmente no que se refere aos conhecimentos de astronomia. Além disso, também foi perguntado aos professores se apresentavam alguma dificuldade em "lidar com os computadores disponíveis no laboratório de informática da escola", os quais são gerenciados pelo sistema operacional Linux.

Quanto a primeira questão, relacionada à formação inicial dos entrevistados, verificou-se que todos possuem formação em biologia, conforme gráfico 1.

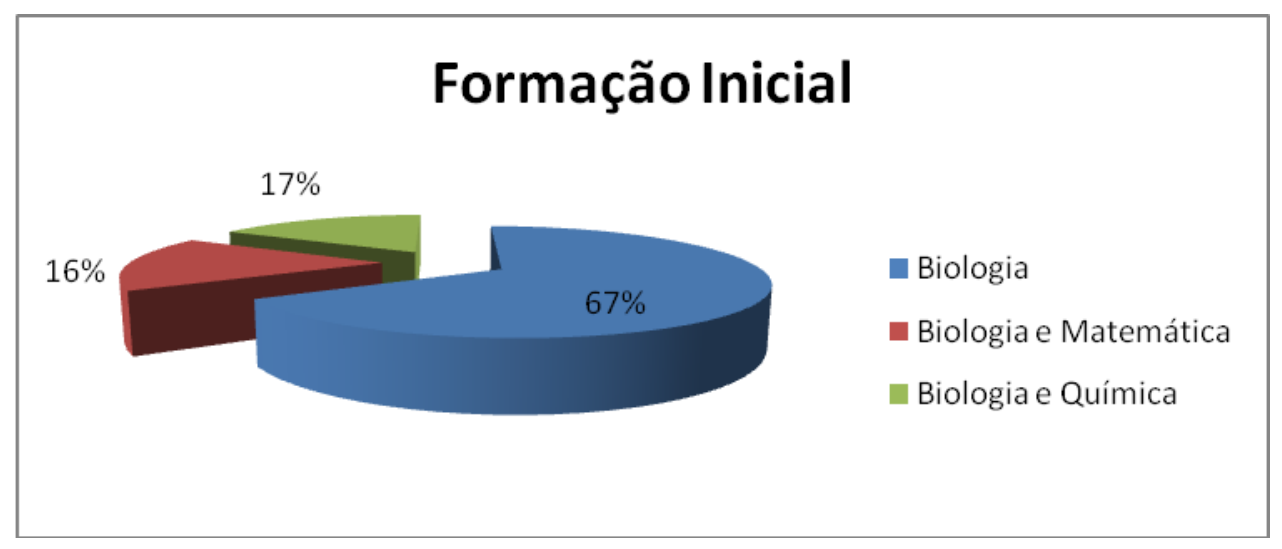

Gráfico 1. Formação Inicial

O segundo e o terceiro questionamentos pautaram-se em verificar se, durante o curso de graduação, os professores entrevistados haviam cursado alguma(s) disciplina(s) específica(s) ou alguma(s) disciplina(s) diversa(s), que tivesse abordado astronomia. As respostas revelaram que, durante o período de formação, nenhum dos professores entrevistados cursou alguma disciplina que tivesse abordado qualquer tópico de astronomia.

Diante dessa constatação, questiona-se: como ensinar aos alunos algo que não se aprendeu? Carvalho e Gil-Perez (2003, p.21) afirmam que se existe um ponto em "que há consenso geral entre os professores - quando se propõe a questão do que nós, professores de Ciências, devemos "saber" e "saber fazer" - é, sem dúvida, a importância concedida a um bom conhecimento da matéria a ser ensinada." Vê-se, portanto, que ensinar algo (Ciências) que não se "domina" se torna uma tarefa difícil, pois, corre-se o risco de pautar o ensino em questões baseadas apenas no senso comum.

Candau (2003) argumenta que a qualidade do ensino está diretamente ligada à formação dos professores. Ela afirma: 
A busca da construção da qualidade de ensino e de uma escola de primeiro e segundo graus comprometida com a formação para a cidadania exigem necessariamente repensar a formação de professores, tanto no que se refere à formação inicial como a formação continuada (CANDAU, 2003, p.140).

$\mathrm{Na}$ quarta questão, os entrevistados foram interrogados sobre sua formação, mais especificamente, se tal formação Ihes fornecera requisitos teóricos suficientes para lecionar astronomia. Obtiveram-se as seguintes respostas:

"Não forneceu nada. Tem que estudar" (Prof1);

"Não, tenho muita dificuldade em astronomia" (Prof2);

"Não, de jeito nenhum" (Prof3);

"Não forneceu, tive que estudar a parte" (Prof4);

"Não, teria que mudar" (Prof5);

"Não, porque não teve aulas" (Prof6)

Verifica-se, por meio dos relatos dos professores entrevistados, que todos têm a convicção de que sua formação inicial não lhes forneceu requisitos mínimos para que pudessem lecionar o conteúdo de astronomia.

Lima e Reali (2002, p. 219) afirmam que as melhorias na educação dependem, dentre outros fatores, da formação dos professores. A autora argumenta também que a "preocupação com a aprendizagem profissional da docência se insere no âmbito das preocupações com a melhoria da qualidade da educação, visto que a formação de professores é apontada como elemento fundamental". Mesmo não sendo considerados como elementos exclusivos nos processos que envolvem melhorias no ensino, "os professores e sua formação não podem ser ignorados nesse processo".

Já na quinta questão, voltou-se a atenção exclusivamente à formação continuada dos educadores: "Você já participou de algum (s) curso (s) de formação continuada sobre astronomia?" Os entrevistados responderam:

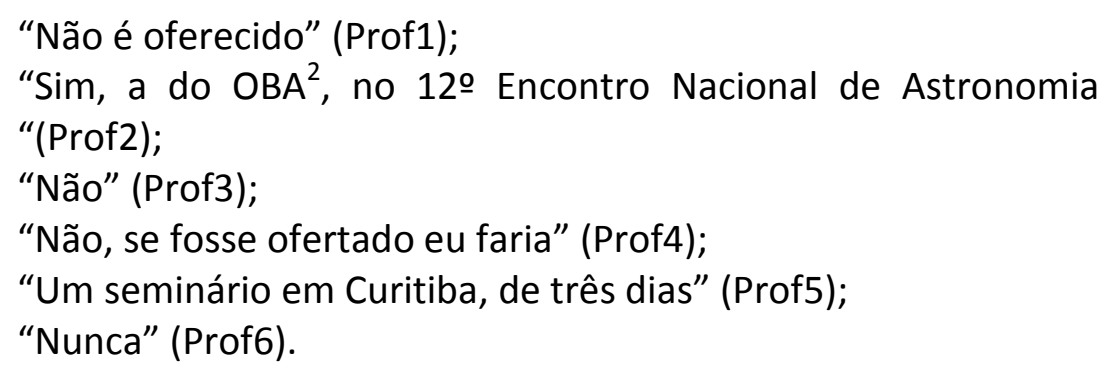

\footnotetext{
${ }^{2}$ A Olimpíada Brasileira de Astronomia é um evento que conta com a participação de escolas públicas e privadas, sem exigência mínima ou máxima de alunos, podendo participar alunos desde o primeiro ano do Ensino Fundamental ao último ano do Ensino Médio. Mais informações podem ser obtidas por meio do acesso a este endereço eletrônico: http://www.oba.org.br.
} 
Os dados revelaram que, até o momento da pesquisa (novembro de 2012), a maior parte dos professores (4) não havia participado de nenhum curso de formação continuada na área de astronomia. Quanto aos dois entrevistados que afirmaram ter participado de curso na área pesquisada se encontravam afastados da função docente, devido a problemas de saúde. Desse modo, vê-se que 66,67\% (4 dos 6) dos professores de Ciências entrevistados, que lecionam no respectivo nível de ensino, atuam sem nenhuma formação específica na área de astronomia. Já a última questão da entrevista realizada com os professores de Ciências buscou verificar se os entrevistados possuíam alguma dificuldade em utilizar os computadores com o sistema operacional Linux.

As respostas ${ }^{3}$ obtidas foram as seguintes:

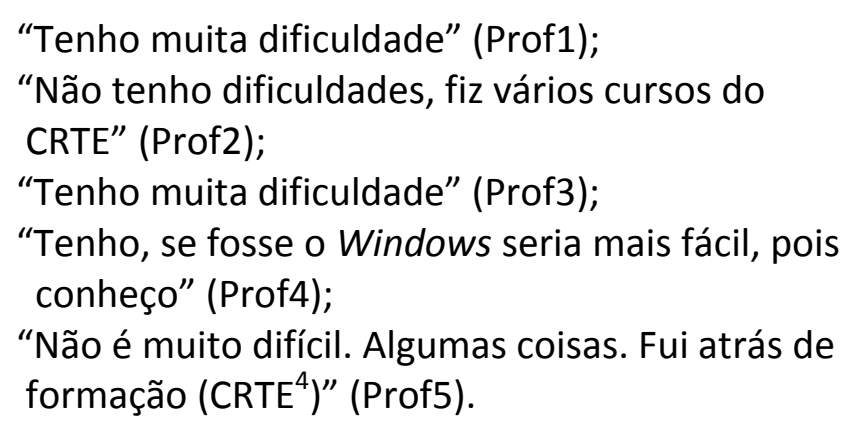

Percebe-se, portanto, que a maioria dos entrevistados argumentou que apresenta dificuldades em utilizar o sistema operacional Linux (presentes nos laboratórios de informática da rede estadual paranaense).

\subsection{Formação de professores quanto à temática astronomia: Análise e Discussões}

Durante o período em que se findavam a coleta e a análise dos dados referentes à pesquisa, apresentou-se a oportunidade de participar da Hora Atividade Interativa (HAI).

A hora atividade interativa foi criada pela SEED, no ano de 2012, sob a responsabilidade da DITEC (Diretoria de tecnologia Educacional), como forma de promover um encontro virtual para fornecer suporte para debates sobre questões relacionadas à educação. Para a SEED, o principal objetivo desses encontros é possibilitar que um grande número de educadores possa discutir e compartilhar informações, abordando temas de interesse mútuo, de forma simultânea, mesmo que se os participantes se encontrem em localidades distantes.

\footnotetext{
${ }^{3}$ Os comentários foram transcritos da mesma forma que se encontram no ambienta virtual, disponível em: http://www.coveritlive.com/index2.php?option=com_altcaster\&task=viewaltcast\&altcast_code=dee71d7ba5\&ipod=y

${ }^{4}$ Coordenação Regional de Tecnologia na Educação de cada Núcleo Regional de Educação do Estado do Paraná; 
No dia 01 de novembro de 2012, a SEED promoveu a HAI ${ }^{5}$ em dois momentos: um, no período matutino, às $10 \mathrm{~h} 20 \mathrm{~min}$, outro, no período vespertino, a partir das $16 \mathrm{~h} 30 \mathrm{~min}$, abordando o tema: "Astronomia no Ensino de Ciências". Durante a HAl realizada no período vespertino, foi possível analisar algumas proposições inerentes ao ensino de astronomia, bem como, sobre a formação dos professores em relação à temática abordada. Os professores participantes debateram algumas questões relativas ao ensino de astronomia no Ensino Fundamental, como, material didático, metodologia e, principalmente, elementos referentes à formação dos próprios professores participantes da HAI. Visando a preservar as identidades desses profissionais, os mesmos serão denominados PHAl1, PHAI2, PHAI3, PHAI4, PHAI5, PHAI6, PHAI7, PHAI8, PHAI9, PHAI10, PAHAI 11 e Equipe SEED, composta por 6 (seis) professores.

Nesse evento, geralmente é a Equipe da SEED que faz a mediação, por meio de questionamentos, promovendo a interação entre os professores participantes. Eis uma de suas primeiras interações:

"Este tema foi sugerido pela maioria dos participantes da primeira HAl. Agradecemos mais uma vez a participação de todos e contamos com sua colaboração" (Equipe SEED, às 15h31min).

A declaração da equipe da SEED evidencia que a temática "astronomia" foi uma reivindicação dos próprios professores de Ciências, sugerindo, portanto, que a mesma é relevante para os educadores, principalmente para aqueles que lecionam Ciências. Na sequência, a equipe inicia a $\mathrm{HAl}$, apresentando o seguinte questionamento:

"A Astronomia é um conteúdo estruturante, devendo ser contemplado no planejamento do professor do 6 으 ao 9 o ano do ensino fundamental.

Professor(a), quais são as dificuldades que você encontra em trabalhar com os conteúdos de Astronomia?"(Equipe SEED, às 15h31min).

Eis algumas das respostas apresentadas pelos professores:

"Boa tarde a todos. Tenho turmas de oitavos e nonos anos, com relação aos nonos anos, consigo abordar temas de astronomia, porém no conteúdo de oitavo ano sinto muita dificuldade. Gostaria mesmo de compartilhar ideias" (PHAI1, às 15h32min). 
A Equipe SEED ainda salientou:

"Observa-se uma certa dificuldade em se trabalhar com os conteúdos de Astronomia devido principalmente a dois fatores: por se tratar de um tema com abordagem multidisciplinar, abrangendo disciplinas como História, Geografia, Filosofia, Física, Química, Matemática e Biologia, e por não fazer parte do currículo de formação acadêmica da maioria dos professores" (Equipe SEED, às 15h32min)

Diante dessa observação, vários professores se manifestaram:

"Geralmente astronomia é lecionado por professores formados em ciências biológicas" (PHAl2, às 15h33min).

"Tenho dificuldade de relacionar o tema no nono ano, fica bem difícil, pois sou formada em Biologia" (PHA3, às 15h33min).

"Moderado a dificuldade depende da série falta de materiais nas escolas e no livro didático" (PHAl4, às 15h34min).

"Boa tarde a todos, respondendo a pergunta da SEED, eu particularmente encontro dificuldades para trabalhar com esse conteúdo, talvez pela falta de materiais" (PHAl5, às 15h34min). "Eu encontro dificuldades em trabalhar Astronomia também" (PHAl6, às 15h35min).

"Devido essa multidisciplinaridade às vezes me sinto insegura em tratar um tópico, pois não tenho tanto conhecimento na área" (PHAI7, às 15h35min).

"Para o 60 ano é fácil, porém para o 9a ano é bem difícil" (PHAl3, às 15h35min).

"Astronomia requer muito conhecimento e domínio. Infelizmente não se tem uma preparação acadêmica para esse tema" (PHAl5, às 15h 35min).

"Tenho dificuldade de abordar o tema, principalmente pela formação" (PHAl8, às 15h35min).

"Como na minha formação não tive a disciplina estou fazendo uma pós em astrobiologia" (PHAl9, às 15h35min).

"Tenho dificuldade em trabalhar Astronomia" (PHA10, às 15h37min).

"Boa tarde a todos. Os alunos do 60 ano adoram astronomia, mas pesquiso muito para sanar suas curiosidades" (PHAl11, às 15h37min).

Diante dos depoimentos, percebe-se que muitos professores pertencentes à rede estadual reconhecem que detêm uma formação precária quanto à temática astronomia. Desse modo, como os educadores poderiam realizar ações, propor questionamentos, promover discussões em torno de um assunto (no caso, astronomia) sobre o qual não dispõem de uma formação mínima? 
Para Lima e Reali (2002), os professores possuem crenças, pensamentos, ideias, concepções sobre as ações e sobre o trabalho docente, os quais são adquiridos praticamente durante a sua formação acadêmica. Sendo assim, acredita-se que (quando se trata do conhecimento a ser ensinado) se torna mais difícil estruturar um trabalho pedagógico quando não se possui formação que subsidie esse processo.

Além disso, uma das concepções pedagógicas bem difundidas na educação é a construtivista, processo segundo o qual professor e aluno podem interagir, mas cabe ao educador a função de proporcionar condições para que o aluno seja capaz de reestruturar seu conhecimento, ou seja, de relacionar seus conhecimentos prévios (senso comum) ao conhecimento científico.

Becker (1994) argumenta que o construtivismo na educação é uma das formas teóricas mais claras, baseadas na ideia de que conhecer é construir. Para ele, o construtivismo defende a ideia de que, a rigor, nada está acabado e que o conhecimento não é algo pronto, ou seja, é fruto das intensas interações que ocorrem entre o sujeito e o meio. De acordo com o autor, essa concepção reúne várias tendências educacionais, tendências essas que estão insatisfeitas com a forma de transmissão de conhecimentos que ainda vigora em muitas escolas, baseadas apenas reproduzir informações e conhecimentos prontos, presentes em livros e manuais didáticos e na figura do professor.

Cachapuz et al. (2005), também baseados na concepção construtivista, enfatizam que é necessário que todos tenham uma educação científica, pois para se formar cidadãos críticos há que se promover a imersão dos alunos em uma cultura científica e, para tanto, é muito importante que a formação inicial e continuada do professor articule epistemologia e didática.

Ao citar alguns dos vários autores que tratam dos processos de ensino e aprendizagem e ainda, fazem referência à tendência construtivista, pretende-se destacar como todas essas ações de "construção do conhecimento" podem efetivar-se se o professor não possuir a mínima formação do tema a ser abordado em sala de aula com seus aluno? Acredita-se, portanto, que ações metodológicas e didáticas empregadas pelos professores terão uma maior possibilidade de sucesso se eles possuírem domínio do conteúdo abordado.

Durante as interações, a "Equipe da SEED", por meio do sistema da HAl, também promoveu enquetes, cujas perguntas abordavam vários aspectos da temática. Uma das questões foi exatamente sobre a formação acadêmica relativa à astronomia: 


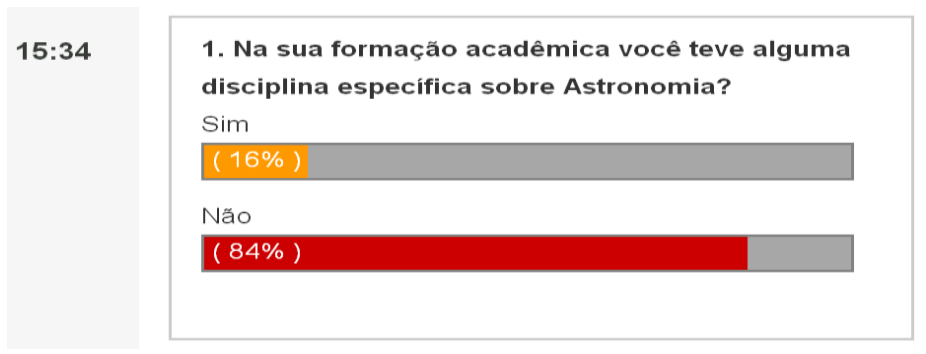

Fonte: SEED-PR, novembro de 2012.

Os dados coletados pela Equipe da SEED durante a HAI corroboraram os resultados obtidos junto aos professores de Ciências que foram entrevistados na escola onde se desenvolveu esta pesquisa, mostrando que a maioria dos professores que lecionam o conteúdo de astronomia nas escolas públicas do estado do Paraná não possui formação específica na referida área.

\section{CONSIDERAÇÕES FINAIS}

Diante dos apontamentos, verifica-se que a maioria dos professores entrevistados, assim como, daqueles que participaram da HAl possuem problemas consideráveis quanto à formação relacionada à temática astronomia, evidenciando certo obstáculo que pode dificultar as ações cotidianas desses professores, quando abordarem conteúdos curriculares relacionados à astronomia.

Verificou-se, também, certo despreparo por parte dos entrevistados para lidar com o sistema operacional Linux, presente nos laboratórios de informática das escolas paranaenses. Nesse sentido, entende-se que a formação de professores, tanto a inicial, quanto a continuada, é um assunto que merece atenção e, principalmente, espera-se que se criem e que se ampliem políticas voltadas à qualificação e formação de professores em todos os níveis de ensino.

\section{REFERÊNCIAS}

ALTET, Marguerite. As competências do professor profissional: entre conhecimentos, esquemas de ação e adaptação, saber analisar In: PERRENOUD, Philippe et. al. (orgs). Formando professores profissionais: Quais estratégias? Quais competências? Porto Alegre: Artmed, cap. 1, p. 23-32, 2001.

BECKER, Fernando. A epistemologia do Professor. Petrópolis: Vozes, 1994.

CACHAPUZ, Antonio et al. A necessária renovação do ensino de ciências. São Paulo: Cortez, 2005.

CANDAU, Vera Maria Ferrão. Formação continuada de professores: tendências atuais In: REALI, Aline Maria de Medeiros Rodrigues e MIZUKANI, Maria da Graça Nicoletti (org). Formação de Professores: Tendências atuais. São Carlos: Edufscar, cap. 9, p. 139-152 2003. 
CARVALHO, Anna Maria Pessoa, GIL-PEREZ, Daniel. A formação dos professores de Ciências. 7. ed. São Paulo: Cortez, 2003.

MAZZOTTI, Alda Judith Alves; GEWANDSZNAJDER, Fernando. O método nas ciências naturais e sociais - pesquisa quantitativa e qualitativa. São Paulo: Pioneira, 1998.

LIMA, Soraiba Miranda e REALI, Aline Maria de Medeiros Rodrigues. O papel da formação básica na aprendizagem profissional da docência: aprende-se a ensinar no curso de formação básica? In: REALI, Aline Maria de Medeiros Rodrigues e MIZUKANI, Maria da Graça Nicoletti (orgs). Formação de professores - Práticas pedagógicas e escola. São Carlos: Edufscar, 2002. 